\title{
Short-Term Research Experience (SRE) in the Traditional Lab: Qualitative and Quantitative Data on Outcomes
}

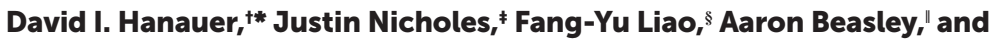 \\ Heather Henter" \\ †English Department, Indiana University of Pennsylvania, Indiana, PA 15705; "English and \\ Philosophy Department, University of Wisconsin-Stout, Menomonie, WI 54751; "Department of \\ Foreign Languages and Literature, National Sun Yat-Sen University, Kaohsiung City 804, Taiwan; \\ "English Department, Union University, Jackson, TN 38305; 'Natural Reserve System, University of \\ California San Diego, La Jolla, CA 92093
}

\begin{abstract}
The San Diego Biodiversity Project introduces undergraduate students at four different 2- and 4-year schools to a short-term research experience (SRE) that was implemented as a module in the last third of a traditional laboratory course. The study assesses the qualities of this SRE for students using three different methods. Twenty-one participants were interviewed about their experiences in the traditional and research components of their course. In a repeated-measures design, 124 participants took the Persistence in the Sciences (PITS) survey immediately before and after their participation in the SRE. Finally, using a propensity score matching technique, PITS survey results for SRE students were compared with those for students in a course-based research experience (CRE). Student perceptions of the traditional lab and the SRE are different-students appreciate learning basic processes and procedures in the traditional lab, but they express having personal investment in and a sense of participating in science in the SRE. Significant increases were found for the variable of Project Ownership in the SRE condition over the traditional lab, but SRE outcomes were lower than CRE outcomes. Although the SRE may not provide the benefits of a CRE, it is a serious option for expanding access to authentic research.
\end{abstract}

\section{INTRODUCTION}

Driven by the economic needs for a science, technology, engineering, and mathematics (STEM)-educated workforce in the United States and the calls for enhanced diversity among STEM researchers, there is increasing pressure on faculty, science departments, and higher education institutions to revise and reform the traditional laboratory course (American Association of University Women [AAUW], 2010; American Association for the Advancement of Science [AAAS], 2011; National Research Council [NRC], 2012; President's Council of Advisors on Science and Technology [PCAST], 2012). There is growing evidence that the quality of the early undergraduate research lab experience is an important component in the persistence of students from a variety of educational backgrounds, ethnicities, and genders in science majors (Nagda et al., 1998; PCAST, 2012; Graham et al., 2013; Auchincloss et al., 2014; Hanauer et al., 2017; Hernandez et al., 2018). Traditional laboratory courses have focused on helping students develop the research skills and procedures required for later, more advanced courses by providing explicit directions for experiments with predetermined and well-established outcomes (Domin, 1999; Weaver et al., 2008; Auchincloss et al., 2014). This approach of providing a safe, known set of procedures with guaranteed outcomes has a pedagogic logic to it. A particular experimental result is evidence that the students have executed the skills and procedures correctly. The process is not complicated by the possibility of an unexpected outcome, and students generally understand the expectations. But this
Stephanie Gardner, Monitoring Editor Submitted Mar 30, 2018; Revised Oct 2, 2018; Accepted Oct 5, 2018

CBE Life Sci Educ December 1, 2018 17:ar64 DOI:10.1187/cbe.18-03-0046

*Address correspondence to: David I. Hanauer (Hanauer@iup.edu).

() 2018 D. I. Hanauer et al. CBE-Life Sciences Education ๑ 2018 The American Society for Cell Biology. This article is distributed by The American Society for Cell Biology under license from the author(s). It is available to the public under an Attribution-Noncommercial-Share Alike 3.0 Unported Creative Commons License (http://creativecommons.org/licenses/ by-nc-sa/3.0)

"ASCB®" and "The American Society for Cell Biology $\circledast "$ are registered trademarks of The American Society for Cell Biology. 
mainstay of undergraduate science education may not promote persistence in the sciences for a variety of students with different demographics (PCAST, 2012; Graham et al., 2013; Hanauer et al., 2017; Hernandez et al., 2018). Students risk developing a naive view of science that does not address the realities of uncertain outcomes, ambiguity of results, and the presence of failure in science (Bencze and Hodson, 1999; Rahm et al., 2003; NRC, 2005).

In response to the need for keeping a range of different student demographics interested in the sciences and for accurately representing the nature of science, one widely supported solution is the involvement of undergraduate students in authentic research experiences (Hanauer et al., 2006, 2012, 2016, 2017; Hanauer and Dolan, 2014; PCAST, 2012; Graham et al., 2013; Auchincloss et al., 2014; Hernandez et al., 2018). While there has been both discussion and contention over what defines and characterizes an authentic research experience, there has recently been some convergence about what this experience is and is not (Spell et al., 2014). Although engaging in the critical thinking required for the process of science is valuable, this in itself is not sufficient to make students' work in the laboratory authentic (Auchincloss et al., 2014; Hanauer et al., 2017). As explicated in a series of studies, a primary feature of authentic research is the requirement that the research conducted by the student is of significance beyond the laboratory classroom (Hanauer et al., 2006, 2012, 2016, 2017; Hanauer and Dolan, 2014; Graham et al., 2013; Auchincloss et al., 2014; Brownell and Kloser, 2015; Rowland et al., 2016, Shortlidge et al., 2017). This significance can take different forms, such as generating new data or analyses to address a scientific question or a social/ environmental issue, but the common theme is that the student's research could be used beyond the social, physical, and temporal setting of the laboratory classroom as part of a broader scientific research or social agenda (Hanauer et al., 2006, 2012, 2016, 2017; Hanauer and Dolan, 2014; Graham et al., 2013; Auchincloss et al., 2014). In this sense, an authentic research experience is one in which the research conducted by the student becomes part of a broader effort to advance scientific knowledge, address public policy, or change behaviors.

While the broader contextualization of the student's efforts is central to the definition of course-based authentic research, previous work suggests that a project does not become an authentic research experience unless the student is engaged with this process (Hanauer et al., 2012; Hanauer and Dolan, 2014). In principle, it would be possible to complete a laboratory course designed as an authentic research experience by following the procedures required but without actually understanding or engaging with the broader scientific questions of the study (Hanauer et al., 2012). In other words, for this to become an authentic research experience for the student actually doing the research, there needs to be a sense of personal connection and engagement with the research and an understanding of the connection of this work to the broader scientific community (Hanauer et al., 2012; Rowland et al., 2016). To address this aspect of the student's self-positioning in relation to the research he or she is doing, we introduced the concept of student project ownership as an additional feature differentiating traditional lab course work from authentic research experiences (Hanauer et al., 2012; Hanauer and Dolan, 2014). As a criterion for measuring the presence of a research experience, project ownership explains the degree to which a student feels engaged with and connected to the research he or she is doing and the degree to which he or she feels that this research is connected to the broader scientific community. High levels of project ownership are indicative of a student who has the experience of being involved in authentic research (Hanauer et al., 2012, 2017; Hanauer and Dolan, 2014; DounasFrazer et al., 2017; Corwin et al., 2018).

The scholarship on providing undergraduate students with research experiences has proposed three central models: 1) the undergraduate research experience (URE), in which an individual student works as a research apprentice in the lab and on the agenda of an established researcher (Seymour et al., 2004; Brownell and Kloser, 2015); 2) the course-based research experience (CRE), in which a whole class of students is involved with a professor's research agenda (Auchincloss et al., 2014); and 3) the inclusive research and education community (iREC), in which a large-scale, multi-institutional research project situates a CRE within a broad community of researchers (Hanauer et al., 2017). While all these approaches involve an authentic research experience-including results that may be important beyond the classroom, the potential to develop student project ownership, and the experience of thinking and acting as a scientist-there are differences among the approaches. In relation to scale, the iREC provides access to authentic research for thousands of students (Hanauer et al., 2017), any individual CRE to all students in a lab course (60 students in one example; Rowland et al., 2016), and a URE to an individual student (see Seymour et al., 2004). Costs per student for implementation are inversely related to scale, with the URE being the costliest of the three (Auchincloss et al., 2014; Hanauer et al., 2017). Finally, there are differences in the timeline for each: the iREC can last up to a year, consisting of multiple terms of work (Hanauer et al., 2017); the CRE is a course that typically lasts for a single term but can be a year (Auchincloss et al., 2014); and the URE can be from several weeks to multiple years (Seymour et al., 2004).

While broad agreement on the need to reform the traditional laboratory course exists (AAUW, 2010; AAAS, 2011; NRC, 2012; PCAST, 2012), and a series of existing models concerning how to transform an entire course have been proposed (Seymour et al., 2004; Auchincloss et al., 2014; Hanauer et al., 2017; CUREnet, https://serc.carleton.edu/curenet/index.html), several barriers may impede actual implementation. Spell et al. (2014) identified barriers perceived by the faculty and departments, including the lack of time, the lack of facilities and personnel to develop a CRE in some institutions (especially those that do not have an existing research infrastructure), large class sizes, and faculty resistance due to concerns about the coverage of required aspects of the curriculum and ways in which they and their students will be evaluated. Shortlidge et al. (2016) also reported on challenges of CRE development, citing the amount of additional time and work required, financial constraints, and student resistance to a relatively ambiguous and uncertain process. For many institutions that do not have primary research roles, such as 2-year colleges and 4-year teaching schools, the internal development of authentic research courses for students can be too difficult to implement (the Community College Undergraduate Research Initiative, www.ccuri.org, is an exception, however). The findings reported by Spell et al. (2014) indicate that adding a research experience to an existing departmental program can be disruptive and can involve a series of 
changes on the levels of individual courses, the program, and personnel.

Considering the importance of authentic research experiences for STEM students and the potential difficulties that some institutions may face in developing CREs, the current project explores an additional model of science education designed to provide a quality research experience for undergraduate science students. In the project studied here, a traditional laboratory course was augmented with a monthlong authentic research project that was implemented at multiple institutions. In this model, conducted at both 2- and 4-year schools, the lead institution's research center collaborates with other institutions by sharing a research agenda. The lead institution develops a set of research protocols and centrally stores and uses the data generated across the entire group. However, unlike the CRE and the iREC, which cover an entire course, the research experience is a module situated within the traditional laboratory class, usually the final month of the course. In this way, it is a hybrid model: students are involved in a traditional laboratory experience for two-thirds of the term, with controlled, predefined experiments, and during the last third of the term, they are exposed to a multi-institutional, authentic research experience. This model, a short-term research experience (SRE), is similar to the CRE model but takes less time. The concept of the SRE presented here builds upon previous pedagogical attempts at integrated mini-research experiences within lab courses. The specific SRE project described here also shares similarities with the iREC model, in that it involves collaboration between multiple institutions, although this may not always be the case, and we can foresee SRE modules implemented at a single institution. The SRE is a planned and scheduled aspect of the course syllabus designed to augment and extend the traditional lab course and provide an authentic research experience.

This SRE approach has several advantages. For those institutions that do not have a developed research infrastructure, it allows students to become involved in a research experience. In the example described here, the research was a collaboration between faculty at a research university and several neighboring community colleges that did not have research labs with URE opportunities for students. The SRE is relatively easy to implement within the current program structure, as it merely changes a portion of an existing class, rather than adding a new course. It should elicit fewer objections from faculty, as it does not involve relinquishing existing beliefs about the importance of structured and safe introductions to scientific skills and procedures. If successful, this approach would allow additional flexibility for schools that would like to include a research experience for students but do not wish to completely overturn existing lab course structures.

The crucial question here is really whether an SRE does indeed provide educational benefits leading to the potential for enhanced student persistence. A series of assessment tools have been developed to explore the values of a research experience. At the forefront of this assessment effort is a recent, psychometrically tested suite of psychosocial tools termed the Persistence in the Sciences (PITS) survey (Hanauer et al., 2016, 2017). Psychosocial variables measure psychological responses in the individual as a result of experiences in the social environment. For example, the PITS survey assesses the degree to which a variable such as Science Identity develops as a result of particular science education experience. This PITS survey has been used to evaluate the relative value of different types of research experiences and offers the current study an approach for looking at the relative value of the SRE following the traditional laboratory course experience (Hanauer et al., 2017).

However, because the SRE is an approach that has not been thoroughly tested, it is prudent to use a mixed-methods design involving qualitative and quantitative data to really explore how students understand and experience the SRE. Hence, beyond the use of the PITS survey, qualitative interview data have been collected and analyzed. The aim here is to see whether the SRE really was different from the traditional laboratory course and determine ways in which this experience might offer benefits beyond the existing traditional lab experience. Specifically, the following research questions were addressed:

1. In what ways do students understand and differentiate between the educational experiences of the traditional lab and the authentic SRE?

2. Are there differences between the authentic SRE and a CRE research experience?

\section{THE SAN DIEGO BIODIVERSITY PROJECT}

The specific SRE that was studied in this paper was the San Diego Biodiversity Project (Butler et al., 2014; Henter et al., 2016). This project aligned with current thinking about authentic student research in that the students' work was part of a broader research effort. Students contributed data to a worldwide effort to document biodiversity. Specifically, students created inventories of invertebrate biodiversity on their campuses or in neighboring ecological reserves; they generated new data on the presence and geographic distribution of hundreds of invertebrate species.

These data are valuable because biodiversity remains poorly understood: despite 250 years of modern taxonomy, most species on Earth have never been named or described. Estimates of the unknown range from $70 \%$ of arthropod species (Hamilton et al., 2010; May, 2010) to 86\% of all eukaryotes (Mora et al., 2011). This knowledge gap is a huge obstacle for environmental stewardship. After all, how can we conserve what we do not know we have? In particular, better documentation of biodiversity is important for Southern California as the area has been designated a hot spot of global conservation importance (Myers et al., 2000).

Students investigated local biodiversity with a technique known as DNA bar-coding. Just as a bar code is used to identify products in a store, a short standardized region of the genome (a "DNA bar code") is used to differentiate taxa (Hebert et al., 2003). This region is variable enough to distinguish species in most cases, yet short enough to be sequenced cost-effectively (about \$10 per individual organism). An international effort to create a reference library of bar codes is ongoing, with more than half a million species already in the Barcode of Life Database (BOLD, https://v4.boldsystems.org; Ratnasingham and Hebert, 2007). Because it is part of a larger research effort, this project shares similarities with the iREC model.

As described earlier, this SRE was conducted at three 2-year colleges and one 4-year university in Southern California. The 
2-year colleges are all designated as Hispanic-serving institutions. All of the participants were enrolled in biology lab or lecture/lab courses. The classes at the different institutions shared many similarities but were not identical. The students were largely biology majors, in their second, third, or fourth year of the major. The lab sections had enrollments from 24 to 36 students, but there were often multiple sections within a course. The courses were either general biology labs required for the major or were one of several upper-division courses that would fulfill major requirements, and in one case, the SRE was conducted in a smaller honors section of a general biology lecture/ lab course. The traditional portion of the course included activities such as repeating experiments from the published literature; developing skills required for future lab work, such as pipetting; and activities that illustrated concepts covered in lecture. The students were not informed ahead of time that their courses would involve authentic research, nor were they given a choice of different research projects. All students who participated in the surveys and interviews participated in both aspects of the course-the traditional part of the lab and the SRE.

During the SRE module, students working in groups of two or three collected arthropod specimens from the field. Although each group collected its own specimens, the latitude students were given in collecting protocol differed from course to course. In some courses, students could collect whatever they found; in other classes, students focused on a specific taxonomic group or habitat; and in yet other courses, the collections were aligned with an ecological experiment. Universally, however, students recorded critical data about their specimens, such as collection date, GPS coordinates, and a photograph. In the lab, they extracted and amplified DNA and sent the DNA to a commercial facility for sequencing. Once they received the sequence data from the facility, they compared their data with the reference library to potentially identify the specimens. With their instructor, students could contribute the resulting data to the professional public database (BOLD) via a student portal specifically designed for the college classroom (BOLD University Student Data Portal, https://uni.boldsystems.org/ index.php/SDP_Home). Through the University Student Data Portal, students shared all of the class data and could see other class's data as well, if the instructors within the project chose to do so. Students were given attribution as they were named as "collectors" in the data portal and subsequently in BOLD.

Although every group in a class attempted to bar-code a specimen, the results varied from group to group. Occasionally, the students were the first to submit a particular taxon to the database. There were always some groups that failed to generate any DNA sequence data, however, and this was discussed as a possibility when conducting original research. After some troubleshooting, groups usually shared data when this happened. Classes differed in how they used the data, from simply looking at the taxonomic diversity of the collections to comparing lab techniques, generating phylogenetic trees, examining DNA polymorphisms, or addressing an ecological hypothesis. In all classes students could compare their specimen with all of the data for that taxa on BOLD. All BOLD entries require GPS coordinates, so students could see the geographic distribution of bar-coded collections of their taxa. It was not uncommon for a student's specimen to be the first record in the region. Similarly, all entries in BOLD require a photograph, so students could see the range of variation in morphology for a taxa. Greater detail about the field, lab, and data-handling techniques can be found in Butler et al. (2014). In sum, the emphasis of the research module was how little is known about biodiversity and how, by documenting invertebrates around their campus, students could contribute original data to the critical scientific effort of addressing this biodiversity knowledge gap.

\section{RESEARCH APPROACH}

The main aim of this research project was to evaluate the potential changes in undergraduate student science education as the result of the addition of an SRE module to an existing traditional course. The study was conducted in three stages: 1) the qualitative understanding of student experiences in the traditional lab and in the SRE; 2) the quantitative evaluation of the psychosocial variables characteristic of an authentic research experience; and 3) a quantitative comparison between the SRE group and a random sample of students studying in a CRE. A CRE was defined through its structural features of being a lab course organized around an authentic scientific question, directed by a central researcher, in which students conducted research and the data were used by the researcher and scientific community for research purposes. To explore these issues, we used the following design for data collection and analysis:

1. Qualitative study: After the completion of the research experience, interview data were collected using a semistructured research-experience interview protocol (Appendix A in the Supplemental Material). The interviews were transcribed and analyzed using a team-developed and validated coding system. In accordance with content analysis approaches to interview data, an emergent coding system was developed, tested for reliability of coding, and used for coding. Coded interviews were tabulated and summarized, offering an analysis of the students' collective understandings of the traditional lab and research experience (Neuendorf, 2017).

2. Quantitative study: Using the PITS survey (Hanauer et al., 2016), longitudinal data were collected at two points: the end of the traditional lab experience (or before the starting point of the research experience) and then at the end of the research experience. Data were analyzed using repeated-measures, one-way analyses of variance (ANOVAs) for six variables of the PITS survey (Project Ownership Content, Project Ownership Emotion, Self-Efficacy, Science Identity, Scientific Community Values, and Networking). This analysis was followed by an analysis of the individual scales that comprise the construct of Project Ownership Content.

3. SRE versus CRE: Using the PITS survey (Hanauer et al., 2016), a random sample of students from the SRE group was compared with a random sample of students from a data set consisting of nine semester-long CRE courses at a research (R1) university not involved in this project. The collection of semester-long research experiences was developed within the context of a single university setting and within the context of a biology department. The CREs covered a range of topics within biology. For comparisons across research experiences and university settings, a propensity score matching approach was used with random student samples. 


\section{METHODS}

\section{Participants}

Two samples of students who had completed both the traditional lab and the SRE participated in this study. Both of these groups were drawn from the overall population of students enrolled in the courses. First, 21 undergraduate students (nine women; 12 men) were interviewed for the qualitative study of SREs. These were students who volunteered after receiving an email invitation sent to all students in the course. Second, 124 students participated in the quantitative study, completing the PITS survey before and after the SRE self-reported demographic characteristics of all groups are in Table 1 (full detail demographic data by class section are presented in Supplemental Table 1). In addition, a comparison group that consisted of a random sample of 61 participants from a data set composed of nine semester-long authentic research courses (CRE) was used for the propensity scores matching analysis. Data were collected in accordance with the institutional review boards of Indiana University of Pennsylvania (Log no. 14-302, obtained by D.I.H.) and the University of California, San Diego (Log no. 161292, obtained by H.H.).

TABLE 1. Demographic Information for quantitative studies (SRE, $n=124 ; C R E, n=61$ )

\begin{tabular}{|c|c|c|c|c|}
\hline \multirow[b]{2}{*}{ Demographic category } & \multicolumn{2}{|c|}{ SRE participants } & \multicolumn{2}{|c|}{ CRE participants } \\
\hline & Frequency & Percentage & Frequency & Percentage \\
\hline \multicolumn{5}{|l|}{ Gender } \\
\hline Male & 52 & 41.9 & 17 & 27.4 \\
\hline Female & 71 & 57.3 & 43 & 69.4 \\
\hline Missing & 1 & 0.8 & 1 & 1.6 \\
\hline \multicolumn{5}{|l|}{ Class Level } \\
\hline Freshman & 8 & 6.5 & 0 & 0 \\
\hline Sophomore & 46 & 37.1 & 56 & 90.3 \\
\hline Junior & 33 & 26.6 & 2 & 3.2 \\
\hline Senior & 19 & 15.3 & 2 & 3.2 \\
\hline Undefined & 18 & 14.5 & 1 & 1.6 \\
\hline \multicolumn{5}{|l|}{ Ethnicity $^{\mathrm{a}}$} \\
\hline American Indian & 3 & 1.6 & 1 & 1.6 \\
\hline Asian & 27 & 14.9 & 10 & 16.1 \\
\hline African American & 9 & 4.9 & 5 & 8.1 \\
\hline Hispanic/Latino & 35 & 19.3 & 5 & 8.1 \\
\hline Hawaiian & 4 & 2.2 & 1 & 1.6 \\
\hline White & 82 & 45.3 & 40 & 64.5 \\
\hline Other & 13 & 7.2 & 0 & 0 \\
\hline Multiethnic & 8 & 4.4 & 1 & 1.6 \\
\hline \multicolumn{5}{|l|}{ GPA } \\
\hline Below 2.5 & 4 & 3.2 & 1 & 1.6 \\
\hline $2.6-3.0$ & 31 & 25 & 11 & 17.7 \\
\hline $3.1-3.5$ & 45 & 36.3 & 35 & 56.5 \\
\hline $3.6-4.0$ & 43 & 34.7 & 14 & 22.6 \\
\hline 4.1 and higher & 0 & 0 & 0 & 0 \\
\hline Missing & 1 & 0.8 & 1 & 1.6 \\
\hline \multicolumn{5}{|l|}{ Parent's educational level } \\
\hline No college degree & 41 & 33.1 & 13 & 21 \\
\hline Associate degree & 24 & 19.4 & 0 & 0 \\
\hline Bachelor's degree & 31 & 25 & 14 & 22.6 \\
\hline Master's degree & 18 & 14.5 & 19 & 30.6 \\
\hline Doctorate or professional degree & 9 & 7.3 & 15 & 24.2 \\
\hline Missing & 1 & 0.8 & 1 & 1.6 \\
\hline \multicolumn{5}{|l|}{ Parent's occupation } \\
\hline Unskilled labor & 13 & 10.5 & 3 & 4.9 \\
\hline Skilled labor & 27 & 21.8 & 7 & 11.5 \\
\hline Clerical & 4 & 3.2 & 1 & 1.6 \\
\hline Service & 9 & 7.3 & 2 & 3.2 \\
\hline Managerial & 25 & 20.2 & 12 & 19.4 \\
\hline Professional & 45 & 36.3 & 36 & 58.1 \\
\hline Missing & 1 & 0.8 & 1 & 1.6 \\
\hline
\end{tabular}

aParticipants could report more than one ethnicity and thus the total number of participants is more than 124 . 


\section{Data-Collection Procedures}

Qualitative Study. The first study was qualitative and involved a semistructured interview protocol. The protocol used for this study consisted of eight central questions in which students were asked to reflect upon their experiences in the traditional lab, and the research experience (SRE), and the comparison between the two. A full version of the interview protocol can be found in Appendix A in the Supplemental Material. The protocol included an equal number of questions directed at the traditional and research portions of the courses, but no attempt was made to equalize the amount of time respondents chose to spend describing either type of experience. Each of the 21 participants was interviewed individually and data were audiorecorded. Interviews were conducted at the end of the course by H.H., who was not an instructor for any course involved in the study.

Quantitative Study. Quantitative data were collected using the PITS survey (Hanauer et al., 2016) via the Web-based survey platform Qualtrics. Students completed the survey during class.

\section{Analysis}

Qualitative Study. The qualitative interview data were initially transcribed and then analyzed using a content analysis approach. As an initial stage, all interviews were read by the four members of the educational research team (D.H., J.N., F.L., and A.B.), and a provisional coding system was proposed. The coding system captured statements relating to students' understandings of their lab experiences in both sections of their course. In accordance with content analysis approaches, the coding system was developed by identifying responses, proposing generalized code categories and specifying the definition of the code. Through a series of readings and rereadings of interview transcripts, a coding system relating to research experiences was developed. At the stage of a full coding system, interrater reliability was assessed. Three raters independently rated responses from six interviews (25\%), and an intraclass correlation coefficient was calculated to establish interrater reliability. The results (intraclass correlation coefficient [ICC] = 0.99) show very high levels of reliability for the coding system when used by the three raters. Areas of coding difficulty were discussed, and a final version of the coding system was established. Table 2 presents the full set of codes, their definitions, and examples for each code taken from the current data set. Following establishment of the stability of the coding system, the full set of 21 interviews was reanalyzed and coded individually by two raters for each interview transcription. Results were tabulated in relation to the total frequency of codes used by participants in relation to their traditional lab and research experiences. Once results were tabulated, a Wilcoxon signedrank test was calculated to explore whether there were systematic differences between the two experiences in terms of the frequency of codes used to describe each experience. This test functions as a paired-difference test for rank-order data and determines whether two dependent samples are significantly different. This nonparametric test does not assume equal intervals between the frequencies of codes and thus does not take into account the scale of difference in the number of times different code categories were stated, but it does offer information on systematic rank differences of codes between the two groups.
Quantitative Study. The central aim of this analysis was to consider the potential differences between the research experience at the end of the traditional lab and at the end of the SRE. As such, the quantitative data consist of the PITS survey items collected at two different time points from each participant and indicated that a repeated-measures approach be taken. Because the sample was relatively small and fell below recommended guidelines of a repeated-measures multivariate analysis of variance, a repeated-measures ANOVA for each of the PITS variables was used. Each of the PITS survey variables was considered a within-subjects factor and analyzed using a singlefactor, repeated-measures ANOVA. This approach, which has the same participants in both the traditional lab and SRE sections of the course, neutralizes the need for analysis of potentially confounding variables at the level of participant characteristics. The covariables that are not covered by this approach relate to course section and institution type. These were not analyzed in the current study, primarily because of the size of the sample. Not including these covariates in the analysis would not change the outcomes of the comparison of the traditional lab and SRE experiences in a repeated-measures design.

SRE versus CRE. As a final analysis, PITS survey variables for the students in the post (SRE) condition were compared with results from students who studied in a full-semester CRE. Because the comparison is between two groups with possible demographic differences, a propensity score matching technique was employed. A random sample of 61 students was elicited from a data set consisting of 162 students studying in nine different CRE courses. Another random sample of 35 students who had completed the post PITS survey was elicited from the SRE group. The propensity score matching technique used here compared the outcome for each student in the SRE group with the average outcomes of students deemed similar using propensity scores from the CRE group. In this analysis, the average treatment effect for the treated (ATET) was calculated for the matched groups on the six PITS survey scores. Participants were matched on the covariates of gender, grade point average (GPA), class level, parents' educational level, parents' occupation, and ethnicity.

\section{RESULTS}

\section{Qualitative Study}

Table 3 presents the code frequencies for interview data organized by total number of responses (across all participants) made in relation to traditional lab and research experiences. The Wilcoxon signed-rank test shows that there is a significant difference in the rank coding of these educational experiences $(W=6, Z=-2.051, p<0.04, r=0.403)$. This result suggests that, when discussing the two modes of the lab course, participants systematically used different frequencies of code indicating a subjective perception that the actual experience was dissimilar and distinguishable. According to this content analysis, participants described each of the educational modes differently.

The most common code used to describe the traditional lab was: "developing foundational knowledge of skills and procedures." Some characteristic statements include "I got a lot of technical skills when I was working in this section" and "It was just kind of having — developing a toolset that you would need." 
TABLE 2. Traditional laboratory and SRE coding system

Code name
Traditional
1. Developing foundational
knowledge of skills and
procedures

2. Helping with future classes

3. Providing hands-on experience and greater understanding of lecture material

4. Results are clearly defined and tied to classroom outcomes such as tests, assignments, and grades and are not important in themselves
5. Procedures used were not interconnected

6. Providing an exciting introduction to biology (processes and procedures)

7. Lab work involved low levels of pressure

SRE

8. Expression of excitement toward research

9. Providing a sense of conducting authentic research
Statements that express that participation in lab work aided in the development of basic knowledge, skills, and procedures in the field of biology

Statements that express the belief that participation in the lab will contribute to future classes in which the student will participate

Statements that express that lab work enhanced the understanding of the lecture material as a result of hands-on nature of the lab

Statements that express that work in the lab was directed toward activities that were part of classroom assessment such as tests, assignments, and grades; any results received not considered important beyond the classroom

Statements that express that the procedures used in the lab were independent of one another and not part of a single research process

Statements that express that working in the lab provided an exciting introduction to the field of biology and the processes and procedures that biological research involves

Statements that express that the work within the lab was not stressful and involved low levels of anxiety

Statements that express a sense of excitement and fulfillment toward the activity of conducting research

Statements that express that the participant felt he or she was in involved in real, authentic research
"I got a lot of technical skills when I was working in this section."

"And I mean I think the central thing was understanding the foundational concepts behind most of the things we are learning."

"It was just kind of having-developing a toolset that you would need."

"Overall I mean it helps me in all my other classes."

"So I was just thinking like, oh, I'll just use this stuff and it'll be used in my upper-division classes."

"It was more practical application of the lectures."

"With lab I feel that it was very valuable to be able to do those concepts yourself in your own hands. For example, like I just mentioned, bacteria. You know the concepts. You would be able to just think of that conceptually. But being able to do it hands-on, be able to see what happens in real life really adds to the experience."

"All the labs, they're like lab reports. You basically filled them out. Usually it's just answering a lot of questions. Sometimes you might have to draw, like, the basic shape of a molecule."

"It's not figuring out an unknown. It's not actual research. It is research in a sense of we're doing an experiment using scientific methods, but it's not research in the sense of hey, this is something we don't fully understand, or something that we don't have a complete picture of."

"I felt like it was more kind of like you're copying the real thing. You're not actually doing something that contributes outside of yourself."

"We're just doing this one time and it's all you'll ever see it again."

"The first section it was just like, "Oh, if you didn't get the results, then you could just like redo it, and it doesn't matter how many times you redo it, you can still get your results and write about it."

"In the first half everything was split apart."

"I think getting that lab experience with biology, I think [that] was really cool experience."

"The first part was really eye-opening."

"The pressure wasn't as intense."

"So it's a lot more of the reality of the situation when in lecture you kind of have things more catered to you and you have a lot more things that if it works, everything works, and it goes magically."

"It was really exciting to see that the research actually worked."

"So I immediately felt like that's an amazing feeling."

"It is true research and it is being used."

"It contributed to my education a little bit more because when you do things and apply to actual life, it's a little bit more, I guess, of a better experience."

"I was able to go out and explore and that is just something I envision biologists doing. Just being able to go out and explore things and understand the animals or understand just the plants and the biology that surrounds them." 
TABLE 2. Continued

\begin{tabular}{ll}
\hline Code name & \multicolumn{1}{c}{ Definition } \\
\hline $\begin{array}{l}\text { 10. Personal lab work is } \\
\text { important to future research, } \\
\text { the scientific community and } \\
\text { contributes to society }\end{array}$ & $\begin{array}{c}\text { Statements that express that lab work } \\
\text { contributes to future scientific } \\
\text { work, involves new discoveries, } \\
\text { and is more broadly important to } \\
\text { the scientific community and } \\
\text { society }\end{array}$
\end{tabular}

11. Provide an exciting experience of making a new discovery

12. Lab work involved the possibility of failure

13. Providing accurate results and being careful about procedures is a personal responsibility

Statements that express that doing research involved the positive experience of making a new discovery

Statements that express that within the lab it was a possibility that experiments and lab procedures would fail

Statements that express that it was a important that any procedure performed in the lab was done responsibly and that it was a
14. Personal investment, engagement and involvement, with the lab work conducted

15. Procedures used were part of a process and interconnected and coherently tied to results

16. Lab work involved application of skill and procedural knowledge to real-world scientific questions

17. Lab work led to talking to friends and family

18. Lab work was beneficial to my future career personal responsibility to ensure that the work was done and reported accurately

Statements that express that the student was personally engaged, involved, and invested in the lab work being conducted

Statements that express that procedures and experiments conducted in the lab were connected and part of a full research process

Statements that express that lab work involved the application of skill and procedural knowledge that had been acquired to real questions and a scientific research agenda

Statements that express that work in the lab was discussed with friends and family

Statements that express that work in the lab was believed to be beneficial to the student's future career beyond the current undergraduate studies
Examples

"When we uploaded to BOLD, that was not just something personal like writing in my own notebook. It was uploading so that others can be able to access that data as well, so it's kind of a bigger community."

"We're actually contributing information that may not be so well known already. We are providing contributions to the scientific community."

"That felt rewarding too, because I feel like, because I am actually putting stuff that I've done out there into the scientific community and, I guess, contributing."

"When they look at the database to see, like, 'Oh, there is this a species that was found in this area of California."'

"Having that thrill of maybe it could be something new that I would find or something that is related to something else."

"It's just nerve-racking every single time, because you don't know if it's going to work or not."

"This in a way is different, because it's, like, well, we don't know if this is actually going to work."

"I was trying to be very meticulous during this whole project, trying to actually do everything correct."

"You feel more of a, I don't know, a responsibility or something to do it for the others, not of just yourself. It's not personal. It's a bigger picture that you're a part of."

"It really kind of highlights the importance of proper procedure and handling of these things. Because even just a small fraction of, like, a piece missing of that gene sequence, you're not going to get an accurate reading. So I mean it did really stress the importance of, like, proper procedure, proper handling of everything."

"Instead of just sitting around watching someone else do it. In smaller groups you're able to do it more yourself; you have more opportunities. So I felt more involved in that process."

"Absolutely I was more engaged with the honors section than I was with the regular section."

"It's a project that you start, so I feel like you become more invested in what you're doing."

"The second part they were all connected and in the end it all showed how they were."

"Because I do understand the way in that it links into the big picture. I know WHY we're doing it."

"And so we're answering a real question, a real-life science question, that will be hopefully answered with the research."

"So it was like basically applying all of the things that we had learned and learning newer stuff again and to apply it to, like, one research-like, actual research project."

"So, like, I just tell my friends about it all the time."

"I did talk about the honors section to some of my friends and my parents. I didn't, I don't think I ever talked about the non-honors part of the course."

"Remember, like, telling my friends and my mom and my dad, look what I'm doing in my bio class!"

"I think that both sections were very helpful in that aspect, because I think that learning the concepts were very important, but also learning the direct career application was also extremely important."

"Knowing ... how DNA bar-coding works-that would be more applicable to a career or studying biology as I go on." 
TABLE 2. Continued.

\begin{tabular}{|c|c|c|}
\hline Code name & Definition & Examples \\
\hline $\begin{array}{l}\text { 19. Increased my interest and } \\
\text { desire to be in a STEM major }\end{array}$ & $\begin{array}{l}\text { Statements that express that work in } \\
\text { the lab made the student more } \\
\text { interested in staying a STEM major }\end{array}$ & $\begin{array}{l}\text { "It was just something that helped me be even more interested in } \\
\text { biology than I was before." }\end{array}$ \\
\hline $\begin{array}{l}\text { 20. I felt like a scientist and part } \\
\text { of the scientific community }\end{array}$ & $\begin{array}{l}\text { Statements that express that, as a } \\
\text { result of working in the lab, the } \\
\text { student felt more like a scientist } \\
\text { and a member of the scientific } \\
\text { community }\end{array}$ & $\begin{array}{l}\text { "I would say the second part, because it felt for me, to feel more } \\
\text { like a scientist." } \\
\text { "As a scientist, I think once you go into the lab, there is that factor } \\
\text { of pressure to get results and you have like a timeline that you } \\
\text { need to meet, like to present your results afterwards. So I think } \\
\text { that the second section makes you feel more like a scientist." } \\
\text { "That must be part of the feeling when you feel like a scientist." }\end{array}$ \\
\hline $\begin{array}{l}\text { 21. Group collaboration was } \\
\text { beneficial and exciting }\end{array}$ & $\begin{array}{l}\text { Statements that express that group } \\
\text { collaboration was a positive and } \\
\text { beneficial aspect of the lab } \\
\text { experience }\end{array}$ & $\begin{array}{l}\text { "I really liked working with other people." } \\
\text { "I think it's more valuable, because you, instead of it just being for } \\
\text { yourself, other people are also collaborating with you." }\end{array}$ \\
\hline
\end{tabular}

Another common code was: "results are clearly defined and tied to classroom outcomes such as tests, assignments and grades and are not important in themselves." For example, one participant stated, "I felt like it was more like you're copying the real thing. You're not actually doing something that contributes outside of yourself." Students were largely positive about the traditional section of the lab. The codes "providing an exciting introduction to biology" and "providing hands-on experience and greater understanding of lecture material" were common and were exemplified by the statements "I think getting that lab experience with biology was a really cool experience" and "It was a more practical application of lectures," respectively. The statement "The pressure wasn't as intense" was typical for the code "lab work involved low levels of pressure." Overall, the picture that emerges of the participants' understanding of the traditional lab is that it develops scientific skills and procedures that are mainly relevant for the course itself. This does not involve high levels of anxiety, and students perceived it as a suitable and enjoyable introduction to the field of biology.

In contrast, one of the participants described the research experience by stating, "You feel more of a, I don't know, a responsibility or something to do it for others, not just for yourself. It's not personal. It's a bigger picture you're part of," which was categorized by the code "providing accurate results and being careful about procedures is a personal responsibility." The most common code to describe the research experience was "providing a sense of conducting authentic research." "It is true research and it is being used" is an example of statement included in this code. "Expression of excitement toward research" was also a common code, exemplified by the

TABLE 3. Code frequencies for interview data organized by total number of statements (across all participants) made in relation to the traditional laboratory and the SRE

\begin{tabular}{|c|c|c|}
\hline Code & Traditional lab & SRE \\
\hline 1. Developing foundational knowledge of skills and procedures & 67 & 2 \\
\hline 2. Helping with future classes & 5 & 1 \\
\hline 3. Providing hands-on experience and greater understanding of lecture material & 16 & 21 \\
\hline $\begin{array}{l}\text { 4. Results are clearly defined and tied to classroom outcomes such as tests, assignments, and grades and are not } \\
\text { important in themselves }\end{array}$ & 34 & 0 \\
\hline 5. Procedures used were not interconnected & 5 & 1 \\
\hline 6. Providing an exciting introductory to biology (processes and procedures) & 18 & 5 \\
\hline 7. Lab work involved low levels of pressure & 13 & 1 \\
\hline 8. Expression of excitement toward research & 4 & 58 \\
\hline 9. Providing a sense of conducting authentic research & 1 & 63 \\
\hline 10. Personal lab work is important to future research, the scientific community and contributes to society & 3 & 35 \\
\hline 11. Provide an exciting experience of making a new discovery & 7 & 14 \\
\hline 12. Lab work involved the possibility of failure & 1 & 20 \\
\hline 13. Providing accurate results and being careful about procedures is a personal responsibility & 1 & 33 \\
\hline 14.Personal investment, engagement, and involvement with the lab work conducted & 2 & 33 \\
\hline 15. Procedures used were part of a process and interconnected and coherently tied to results & 6 & 26 \\
\hline 16. Lab work involved application of skill and procedural knowledge to real-world scientific questions & 0 & 14 \\
\hline 17. Lab work led to talking to friends and family & 7 & 24 \\
\hline 18. Lab work was beneficial to my future career & 7 & 28 \\
\hline 19. Increased my interest and desire to be in a STEM major & 1 & 12 \\
\hline 20. I felt like a scientist and part of the scientific community & 7 & 28 \\
\hline 21. Group collaboration was beneficial and exciting & 1 & 13 \\
\hline
\end{tabular}


TABLE 4. Means and standard deviations for six PITS survey variables for the traditional laboratory and the SRE

\begin{tabular}{lcc}
\hline Variable & $\begin{array}{l}\text { Traditional } \\
\text { laboratory }\end{array}$ & SRE \\
\hline Project Ownership Content & $3.62(0.79)$ & $3.84(0.72)$ \\
Project Ownership Emotion & $3.75(0.76)$ & $3.82(0.77)$ \\
Self-Efficacy & $4.12(0.63)$ & $4.19(0.63)$ \\
Scientific Identity & $3.93(0.85)$ & $3.99(0.95)$ \\
Scientific Community Values & $5.28(0.64)$ & $5.32(0.62)$ \\
Networking & $3.48(0.83)$ & $3.57(0.82)$ \\
\hline
\end{tabular}

statement "It was exciting to see that the research actually worked." But students expressed the opposite emotion as well: "It's just nerve-wracking every single time because you don't know if its going to work or not," which was included in the code "lab work involved the possibility of failure." The comment "We're actually contributing information that may not be so well known already. We are providing contributions to the scientific community" exemplifies the code "personal lab work is important to future research, the scientific community and contributes to society." Another student stated a similar reaction this way, "When we uploaded to BOLD, that was not just something personal like writing in my own notebook. It was uploading so that others can be able to access that data as well, so it's kind of a bigger community." Overall, the participants' descriptions of the research module suggest that this was an authentic research experience for them. The group reported excitement and engagement at conducting research, took on both the personal responsibilities and anxieties involved in conducting original research, and saw this work as part of a broader scientific activity to which they could contribute. They also found it valuable for their future careers and reported higher levels of interest in STEM and feeling like a scientist.

The activities in both the traditional section and the research section of the course were found to contribute to procedural knowledge and understanding of the lecture material as seen in relatively close frequencies for the code "providing hands-on experience and greater understanding of lecture material."

\section{Quantitative Study}

For further insight into the potential differences between the traditional laboratory and research experiences, a series of repeated-measures ANOVAs were calculated for each of the component variables of the PITS survey. As explained earlier, data were collected at the end of the traditional section of the course and at the end of the research experience. All data were matched across participants, and only those students who had completed surveys at both time points were included in the analysis. Table 4 presents the means and standard deviations for all PITS survey variables after the traditional lab and the research experience. For all variables, the research experience involves a slight increase ranging from 0.04 to 0.22 on a fivepoint scale over the traditional lab. The biggest difference concerns the Project Ownership Content variable, with a 0.22 increase for the research experience condition. For further evaluation of the differences in the responses to the two experiences, a series of repeated-measures ANOVAs were calculated. The assumptions of normality and sphericity were tested, and no assumption was violated. Table 5 presents the results of this analysis. Only the variable of Project Ownership Content reached significance, $F(1,69)=3.919, p<0.05$. All other variables were nonsignificant.

Because the variable of Project Ownership Content was found to be significantly different between the traditional lab and research experience sections of the course, and to evaluate the validity of the variable of Project Ownership for the traditional lab students, it was decided to further analyze potential differences between the educational experiences in relation to the 10 individual scales that comprise the construct of Project Ownership Content. A series of repeated-measures ANOVAs were calculated for each of these. The assumptions of normality and sphericity were tested, and no assumption was violated. Table 6 presents the descriptive data for the comparison of the two educational experiences across the scales. The research experience had higher ratings than the traditional laboratory across all the items, except for the item, "I had a personal reason for choosing the research project I worked on," which stayed the same. Table 7 presents the results of the repeated-measures ANOVAs. Significant differences between the educational experiences with increased ratings for the research experience were found for the following four items: "My findings were important for the scientific community," $F(1,69)=$ 4.99, $p<0.03$; "In conducting my research project, I actively sought advice and assistance," $F(1,69)=4.68, p<0.03$; "My research project was interesting," $F(1,69)=5.74, p<0.02$; and "My research project was exciting," $F(1,69)=4.68, p<0.03$. These items should be comprehensible and valid within the context of the traditional laboratory. None of the other rating scales were found to be significantly different for the two educational sections of this course.

\section{SRE versus CRE}

As a final analysis and to evaluate the potential value of an SRE in relation to longer-term research experiences, PITS survey variables for the students in the post (SRE) condition were compared with results from students who studied in a

TABLE 5. Repeated-measures ANOVAs for five PITS survey variables for the traditional laboratory (time 1) and SRE (time 2)

\begin{tabular}{lcccccc}
\hline Variable & Mean square & $d f$ & $\boldsymbol{F}$ & $\boldsymbol{p}$ value & Greenhouse-Geisser & Partial eta squared \\
\hline Project Ownership Content & 1.607 & 1,69 & 3.919 & 0.05 & 0.05 & 0.054 \\
Project Ownership Emotion & 0.13 & 1,69 & 0.331 & 0.57 & 0.57 & 0.005 \\
Self-Efficacy & 0.134 & 1,69 & 0.378 & 0.54 & 0.54 & 0.093 \\
Science Identity & 0.056 & 1,42 & 0.113 & 0.74 & 0.74 & 0.003 \\
Scientific Community Values & 0.054 & 1,69 & 0.21 & 0.65 & 0.28 & 0.003 \\
Networking & 0.311 & 1,69 & 1.2 & 0.28 & 0.017 \\
\hline
\end{tabular}


TABLE 6. Means and standard deviations for 10 Project Ownership Content scales for the traditional laboratory and the SRE

\begin{tabular}{lrr}
\hline Project Ownership Content scale & Traditional laboratory & SRE \\
\hline My research will help to solve a problem in the world. & $3.4(1.06)$ & $3.63(1.01)$ \\
My findings were important to the scientific community. & $3.33(1.07)$ & $3.67(0.96)$ \\
I faced challenges that I managed to overcome in completing my research project. & $3.7(0.91)$ & $3.83(0.92)$ \\
I was responsible for the outcomes of my research. & $4.04(0.92)$ & $4.26(0.79)$ \\
The findings of my research project gave me a sense of achievement. & $3.94(1.03)$ & $3.2(1.04)$ \\
I had a personal reason for choosing the research project I worked on. & $3.32(0.95)$ & $3.11(0.88)$ \\
The research question I worked on was important to me. & $3.79(1.02)$ & $3.48(1.08)$ \\
In conducting my research project, I actively sought advice and assistance. & $3.87(0.93)$ & $4.07(0.89)$ \\
My research project was interesting. & $3.71(1)$ & $4.19(0.86)$ \\
My research project was exciting. & $4(0.92)$ \\
\hline
\end{tabular}

full-semester CRE at an R1 research university. Table 1 presents a demographic comparison of the two groups. All participants completed the same version of the PITS survey (Hanauer et al., 2016). Following the elicitation of a random sample, a propensity score matching technique was used to address imbalances in underpinning demographic variables. Groups were matched on the covariates of gender, GPA, class level, parents' educational level, parents' occupation, and ethnicity. For evaluation of the quality of the propensity score matching, standardized differences and variance ratios were calculated for the matched groups. The majority of the covariates had standardized differences that were close to $0( \pm 0.1)$ and variance ratios that were close to $1( \pm 0.10)$. The exception was for the covariates of class level (standardized difference: -0.37 ; variance ratio: 0.77 ) and parents' education (standardized difference: -0.48 ; variance ratio: 0.71 ). As such, the groups were matched, except for the covariates of class level and parents' education. Potentially class level and parents' education could function as confounding variables in comparative analyses of the two educational groups, and some subsequent analysis was required.

For evaluation of whether these unmatched variables had a significant impact on the PITS variables (and could be confounding variables), a series of linear regressions were conducted with each of the PITS variables as a dependent variable and class level and parents' education as independent variables. The results of the regression analyses reveal that none of the models were significant, and very minimal levels of variance were explained by the independent variables of class level and parents' education (Project Ownership Content: $R^{2}=0.04$, $F(2,92)=1.66, p=0.19$; Project Ownership Emotion: $R^{2}=0.01$, $F(2,93)=0.58, p=0.56$; Self-Efficacy: $R^{2}=0.03, F(2,93)=$ $1.22, p=0.29$; Science Identity: $R^{2}=0.01, F(2,72)=0.44, p=$ 0.65; Scientific Community Values: $R^{2}=0.02, F(2,93)=0.94$, $p=0.39$; Networking: $\left.R^{2}=0.05, F(2,93)=2.6, p=0.08\right)$. Although none of these models was significant, further consideration was given to the individual predictors of class level and parents' education in relation to each of the PITS survey variables. A consideration of the coefficients in each of the analyses revealed that only parents' education had a significant impact on the outcome of the Networking variable $(\beta=-0.23, p<0.03)$. For all the other PITS survey variables, parents' education did not have any significant impact. Class level did not have a significant impact on any of the PITS survey measures. Overall, the results of this analysis suggest that class level and parents' education did not function as confounding variables in the propensity matched groups, even though matching on these variables was not optimal.

Having evaluated the potential confounding of the variables class level and parents' education, it is possible to address the broader issue of matched-group comparisons. Table 8 presents the results of the propensity score analysis. There are significant differences between the groups on all measures, except for Scientific Community Values. A consideration of the descriptive data shows higher ratings for participants from the CRE than for participants from the SRE group.

TABLE 7. Repeated-measures ANOVAs for 10 Project Ownership Content scales for the traditional laboratory and the SRE

\begin{tabular}{|c|c|c|c|c|c|c|}
\hline Project Ownership Content scale & $\begin{array}{l}\text { Mean } \\
\text { square }\end{array}$ & $d f$ & $F$ & $p$ value & $\begin{array}{l}\text { Greenhouse- } \\
\text { Geisser }\end{array}$ & $\begin{array}{c}\text { Partial eta } \\
\text { squared }\end{array}$ \\
\hline My research will help to solve a problem in the world. & 1.83 & 1,69 & 2.418 & 0.12 & 0.12 & 0.03 \\
\hline My findings were important to the scientific community. & 4.11 & 1,69 & 4.99 & 0.03 & 0.03 & 0.07 \\
\hline $\begin{array}{l}\text { I faced challenges that I managed to overcome in completing my research } \\
\text { project. }\end{array}$ & 0.58 & 1,68 & 1.11 & 0.29 & 0.29 & 0.02 \\
\hline I was responsible for the outcomes of my research. & 1.61 & 1,69 & 2.65 & 0.11 & 0.11 & 0.04 \\
\hline The findings of my research project gave me a sense of achievement. & 1.03 & 1,69 & 1.25 & 0.27 & 0.27 & 0.02 \\
\hline I had a personal reason for choosing the research project I worked on. & 0 & 1,69 & 0 & 1 & 1 & 0.05 \\
\hline The research question I worked on was important to me. & 0.88 & 1,68 & 1.16 & 0.29 & 0.29 & 0.02 \\
\hline In conducting my research project, I actively sought advice and assistance. & 2.86 & 1,69 & 4.68 & 0.03 & 0.03 & 0.06 \\
\hline My research project was interesting. & 3.46 & 1,69 & 5.74 & 0.02 & 0.02 & 0.07 \\
\hline My research project was exciting. & 2.89 & 1,68 & 4.68 & 0.03 & 0.03 & 0.06 \\
\hline
\end{tabular}


TABLE 8. Means, standard deviations, and average treatment effects on the treated (ATET propensity score matching) for SRE and CRE courses $(n=96)$

\begin{tabular}{|c|c|c|c|c|c|c|c|}
\hline Estimation method & & $\begin{array}{c}\text { Project Ownership } \\
\text { Content }\end{array}$ & $\begin{array}{l}\text { Project Ownership } \\
\text { Emotion }\end{array}$ & Self-Efficacy & Science Identity & $\begin{array}{c}\text { Scientific } \\
\text { Community Values } \\
\end{array}$ & Networking \\
\hline $\operatorname{SRE}(n=35)$ & & $3.64(0.13)$ & $3.63(0.15)$ & $4.05(0.12)$ & $3.91(0.26)$ & $5.31(0.08)$ & $3.38(0.14)$ \\
\hline $\operatorname{CRE}(n=61)$ & & $4.16(0.05)$ & $4.06(0.08)$ & $4.49(0.05)$ & $4.13(0.07)$ & $5.36(0.08)$ & $3.73(0.12)$ \\
\hline ATET & Coefficient & -0.74 & -0.68 & -0.66 & -0.3 & -0.3 & -0.66 \\
\hline propensity & SE & 0.14 & 0.27 & 0.09 & 0.13 & 0.16 & 0.19 \\
\hline score & $z$ & -5.29 & -2.42 & -6.9 & -2.34 & -1.88 & -3.48 \\
\hline matching & $p$ value & 0.0001 & 0.02 & 0.0001 & 0.02 & 0.06 & 0.0001 \\
\hline
\end{tabular}

\section{DISCUSSION}

This study aimed to evaluate the benefit of the SRE, to investigate how students understand this experience, and to measure any developments in psychosocial variables that may occur as a result of participation in this research experience. The outcomes of the study suggest that the addition of the SRE module did indeed change students' perceptions of their educational experience. The qualitative data, which reflect students' reporting of their experiences and their understandings of the two sections of the course, present a very different profile for the two educational experiences. The traditional lab was presented by students as a self-enclosed educational experience that can develop knowledge of biology and relevant skills and procedures. The SRE was presented as an authentic research experience in which students were engaged and excited and had a real sense of both participating in science and making a contribution to the scientific community. As expressed in students' verbal statements, the SRE involved personal investment, responsibility, accuracy, and a relationship with real science. Whereas the traditional laboratory experience was seen as important for future classes, the research experience was seen as tied to a real-world scientific community and important for becoming a true STEM professional. The qualitative data and subsequent inferential analysis suggest that the traditional laboratory and SRE were experienced differently by participants.

While the qualitative data provide insight into the differences in students' understanding of the two educational components of this course, the quantitative data measure the exact changes between the two sections. In this sense, the quantitative data provide an indication of specifically where and to what degree the addition of an SRE module changed results of the psychosocial variables used to measure research experiences. The results specify that it was only the variable of Project Ownership Content that reached significant levels of difference between the educational experiences. The results suggest that the SRE does increase a sense of project ownership. A detailed analysis of the individual scales of the Project Ownership Content variable pinpoints the specific site of the changes between the two sections. Specifically, students feel increased levels of interest and excitement about doing SRE laboratory research and see this work as important to the broader scientific community. Moreover, while doing this work (and probably as an outcome of the importance of the data for the scientific community), they had enhanced levels of seeking advice and help with their research. These results seem to reinforce the expressed understandings of the research experience found in the interview data.

The final analysis presented in this study compares random samples of students from the SRE with students who studied in a full-semester research experience (CRE). The results show an advantage for the CRE on all the psychosocial variables of the PITS survey, except for Scientific Community Values. There was a potential confounding effect of parents' education on the variable of Networking that cannot be discounted. However, for the variables of Project Ownership Content, Project Ownership Emotion, Self-Efficacy, and Science Identity, the CRE seems to have measurable advantages over the SRE. This final analysis does suggest that there are potential differences in having a semester-long research experience as compared with a monthlong SRE, with an advantage for the CRE. However, the size of the sample and lack of optimal matching of covariates would suggest that further research is needed to be more confident in the comparison of the SRE and CRE student outcomes.

There are also limitations in the interpretation of the other methods used in this study. Interview data were collected at the end of the course following the SRE and a month after the end of the traditional lab component of the semester. The timing of the interview collection could potentially interact with the statements made about both of the sections of this course. Additionally, the fact that some of the students experienced the research in an honors section of the course may have biased their perceptions. Also, in accordance with the practice of the PITS survey administration (Hanauer et al., 2017), data were collected at the end of the traditional lab and at the end of the SRE, but no baseline data were collected at the beginning of the course. Accordingly, we do not know about the incoming rating levels of participants on the PITS survey and cannot compare later ratings at the end of the traditional lab component or the SRE with initial ratings. Finally, as the sample size was relatively small, no secondary psychometric validation was done on the PITS survey with the specific group of students who are the focus of this study.

Despite these limitations, the strongest evidence in this study consists of the PITS survey data in the repeated-measures comparison, which show that what the SRE contributes to the traditional lab course is an increased sense of project ownership. The development of an increased sense of project ownership has been shown in other studies to be an important component of increased engagement and persistence in the sciences (Hanauer et al., 2016, 2017; Corwin et al., 2018). Thus, the development of project ownership through the inclusion of an SRE has value.

More broadly, the data suggest an interesting differentiation between the two sections of the course, with value assigned to both. The traditional lab was seen to have value in terms of what it was designed for: developing foundational skills and 
procedures and providing a positive introduction to biology content. As seen in the qualitative data, the SRE at the end of the semester provides students with a sense of participating in authentic research involving enhanced levels of excitement and engagement. They expressed an increased feeling of personal responsibility and the sense of working as scientists as members of a real scientific project.

The SRE we describe here involved multiple institutions. It is important to note that three of the four schools were 2-year colleges. Community colleges account for nearly half of all U.S. undergraduates and more than half of Hispanic and Native American undergraduates (American Association of Community Colleges, 2018); thus, exploring interventions in this setting is vital (Henter et al., 2016). The instructors all found the collaboration among institutions valuable, but this study did not investigate whether the multi-institutional nature of the project was responsible for any of the student results. We hypothesize that an SRE conducted within a single institution would confer the same benefits that we document here.

In sum, the results suggest that the SRE does add value to the science education of the students in these courses and that the addition of this course component can provide an authentic research experience that increases a sense of project ownership. This is not an insignificant achievement for a course of this type and suggests that the SRE may have a role in the improvement of the traditional laboratory course so that it is capable of engaging students and thereby supporting their persistence. The fact that the SRE has increased practical and economic flexibility when compared with CRE models of authentic research education and could be less intrusive and easier to implement than other options may be especially true in the community college context.

The SRE, while having advantages over the traditional lab in terms of project ownership, has lower outcomes than the semester-long CRE, which still seems to offer a richer research experience. But even if improvements over the traditional lab are limited to the enhancement of a student's sense of project ownership, this would still be a valuable move forward. Importantly, the implementation of a new SRE would seem to be far simpler and face fewer hurdles than the implementation of a new CRE. As the SRE can be situated in an existing course, there is less need to overhaul the whole of the first- and second-year curriculum. Furthermore, because the SRE involves a hybrid model that includes components of the traditional lab, faculty concerns over student ability to acquire basic lab abilities and competencies can be mollified. This should allow the SRE to have increased levels of faculty support for the incorporation of early research experiences in the curriculum. Finally, because the SRE is of shorter duration, costs will presumably be lower than the full CRE, and it should be easier to attain appropriate levels of budgetary support. Overall, the recommendation here is that the SRE is a serious option for enhancing the traditional laboratory for students in a wider range of educational settings and offering the possibility that a broader set of students will have access to an authentic research experience.

\section{ACKNOWLEDGMENTS}

We thank Jim Gilardi, Kathryn Nette, and Nick Reeves for their enthusiastic participation in the San Diego Biodiversity Project. This research was supported by National Science Foundation EAGER award \#1446563.

\section{REFERENCES}

American Association for the Advancement of Science. (2011). Vision and change in undergraduate biology education: A call to action. Washington, DC.

American Association of Community Colleges. (2018). Fast Facts from Our Fact Sheet. Retrieved August 29, 2018, from www.aacc.nche.edu/ research-trends/fast-facts

American Association of University Women. (2010). Why so few? Women in science, technology, engineering and mathematics. Washington, DC.

Auchincloss, L. C., Laursen, S. L., Branchaw, J. L., Eagan, K., Graham, M., Hanauer, D. I., Lawrie, G., ... Dolan, E. L. (2014). Assessment of coursebased undergraduate research experiences: A meeting report. CBE-Life Sciences Education, 13, 29-40.

Bencze, L., \& Hodson, D. (1999). Changing practice by changing practice toward more authentic science and science curriculum development Journal of Research in Science Teaching, 36, 521-539.

Brownell, S., \& Kloser, M. J. (2015). Toward a conceptual framework for measuring the effectiveness of course-based undergraduate research experiences in undergraduate biology. Studies in Higher Education, 40, 525544.

Butler, M., Henter, H., \& Mel, S. (2014). From bugs to barcodes: Using molecular tools to study biodiversity. Proceedings of the Association for Biology Laboratory Education, 35, 41-55.

Corwin, L. A., Runyon, C. R., Ghanem, E., Sandy, M., Clark, G., Palmer, G. C., .. Dolan, E. L. (2018). Effects of discovery, iteration, and collaboration in laboratory courses ion undergraduates research career intentions fully mediated by student ownership. CBE-Life Sciences Education, 17, ar20

Domin, D. (1999). A review of laboratory instruction styles. Journal of Chemical Education, 76, 543-547.

Dounas-Frazer, D. R., Stanley, J. T., \& Lewandowski, H. J. (2017). Student ownership of projects in an upper-division optics laboratory course: A multiple case study of successful experiences. Physical Review of Physics Education Research, 13, 020136, 1-22.

Graham, M., Frederick, J., Byars-Winston, A., Hunter, A.-B., \& Handelsman, J. (2013). Increasing persistence of college students in STEM. Science, 341 , 1455-1456.

Hamilton, A. J., Basset, Y., Benke, K. K., Grimbacher, P. S., Miller, S. E., Novotny, V., ... Yen, J. D. L. (2010). Quantifying uncertainty in estimation of tropical arthropod species richness. American Naturalist, 176, 90-95. doi: $10.1086 / 652998$

Hanauer, D. I., \& Dolan, E. (2014). The Project Ownership Survey: Measuring differences in scientific-inquiry experiences. CBE-Life Sciences Education, 13, 149-158.

Hanauer, D. I., Frederick, J., Fotinakes, B., \& Strobel, S. A. (2012). Linguistic analysis of project ownership for undergraduate research experiences. CBE-Life Sciences Education, 11, 378-385.

Hanauer, D. I., Graham, M. J., Betancur, L., Bobrownicki, A., Cresawn, S. G. Garlena, R. A., ... Hatfull, G. F. (2017). An inclusive research education community (iREC): Impact of the SEA-PHAGES program on research outcomes and student learning. Proceedings of the National Academy of Sciences USA, 114, 13531-13536.

Hanauer, D. I., Graham, M., \& Hatfull, G. F. (2016). A measure of student persistence in the sciences (PITS). CBE-Life Sciences Education, 15, ar54

Hanauer, D. I., Jacobs-Sera, D., Pedulla, M. L., Cresawn, S. G., Hendrix, R. W., \& Hatfull, G. F. (2006). Teaching scientific inquiry. Science, 314, 1880-1881.

Hebert, P. D. N., Cywinska, A., Ball, S. L., \& deWaard, J. R. (2003). Biological identifications through DNA barcodes. Proceedings of the Royal Society B 270, 313-321. doi: 10.1098/rspb.2002.218

Henter, H. J., Imondi, R., James, K., Spencer, D., \& Steinke, D. (2016). DNA barcoding in diverse educational settings: Five case studies. Philosophical Transactions of the Royal Society, 371, 20150340. https://doi .org/10.1098/rstb.2015.0340

Hernandez, P. R., Woodcock, A., Estrada, M., \& Wesley Schultz, P. (2018). Undergraduate research experiences broaden diversity in the scientific workforce. BioScience, 68, 204-211.

May, R. M. (2010). Tropical arthropod species, more or less? Science, 329 41-42. doi: 10.1126/science.1191058 
Mora, C., Tittensor, D. P., Adl, S., Simpson, A. G. B., \& Worm, B. (2011). How many species are there on Earth and in the ocean? PLoS Biology, 9 e1001127. doi: 10.1371/journal.pbio.1001127

Myers, N., Mittermeier, R. A., Mittermeier, C. G., da Fonseca, G. A. B., \& Kent J. (2000). Biodiversity hotspots for conservation priorities. Nature, 403 , $853-858$.

Nagda, B., Gregerman, S., Jonides, J., von Hippel, W., \& Lerner, J. (1998). Undergraduate student-faculty research partnerships affect student retention. Review of Higher Education, 22, 55-72.

National Research Council (NRC). (2005). America's lab report: Investigations in high school science. Washington, DC: National Academies Press.

NRC. (2012). Discipline-based education research: Understanding and improving learning in undergraduate science and engineering. Washington, DC: National Academies Press.

Neuendorf, K. A. (2017). The content analysis guidebook (2nd ed.). Los Angeles: Sage.

President's Council of Advisors on Science and Technology. (2012). Engage to excel: Producing one million additional college graduates with degrees in science, technology, engineering, and mathematics. Washington, DC: U.S. Government Office of Science and Technology.

Rahm, J., Miller, H. C., Hartley, L., \& Moore, J. C. (2003). The value of an emergent notion of authenticity: Examples from two student/teacher scientist partnership programs. Journal of Research in Science Teaching, 40, 737-756.
Ratnasingham, S., \& Hebert, P. D. N. (2007). BOLD: The Barcode of Life Data System (www.barcodinglife.org). Molecular Ecology Notes, 7, 355-364. doi: 10.1111/j.1471-8286.2007.01678.x

Rowland, S., Pedwell, R., Lawrie, G., Lovie-Toon, J., \& Hung, Y. (2016). Do we need to design course-based undergraduate research experiences for authenticity? CBE-Life Sciences Education, 15, ar79.

Seymour, E., Hunter, A.-B., Laursen, S. I., \& DeAntoni, T. (2004). Establishing the benefits of research experiences for undergraduates in the sciences: First findings from a three year study. Science Education, 88, 493534.

Shortlidge, E. E., Bangera, G., \& Brownell, S. E. (2016). Faculty perspectives on developing and teaching course-based undergraduate research experiences. BioScience, 66, 54-62.

Shortlidge, E. E., Bangera, G., \& Brownell, S. E. (2017). Each to their own CURE: Faculty who teach course-based undergraduate research experiences report why you too should teach a CURE. Journal of Microbiology and Biology Education, 18, 1-11.

Spell, R. M., Guinan, J. A., Miller, K. R., \& Beck, C. W. (2014). Redefining authentic research experiences in introductory biology laboratories and barriers to their implementation. CBE-Life Sciences Education, 13 102-110.

Weaver, G. C., Russell, C. B., \& Wink, D. J. (2008). Inquiry-based and research-based laboratory pedagogies in undergraduate science. Nature Chemical Biology, 4, 577-580. 